\title{
Sources of occupational stress among nurses in five countries
}

\author{
Sharon Glazer ${ }^{*}$, Anett Gyurak ${ }^{1}$ \\ San José State University, Department of Psychology, One Washington Square, San José, CA 95192-0120, USA
}

\begin{abstract}
Content analysis on nurses' perception about the nature of occupational stress was performed in this study to identify emic and etic experiences of occupational stress. Nurses from Hungary, Israel, Italy, U.K., and the U.S., gave their responses in writing to the question: "What causes you the most stress or anxiety on your job?" in the dominant tongue of their country. Results indicate both etic and emic sources of job-related stress. 'Performing certain tasks' and 'type of patients' were invariant sources of stress across all five nations. Furthermore, nurses in the U.K. reported 'skillset of staff' as a source of stress and Hungarian nurses indicated 'low salary' and 'lack of resources' as sources of job stress more frequently than nurses in the other nations of this study.

(C) 2007 Elsevier Ltd. All rights reserved.
\end{abstract}

Keywords: Occupational stress; Cross-cultural; Nurses; Stressors; Sources of stress

\section{Introduction}

Most studies of occupational stress among nurses have been conducted quantitatively and in single countries (for reviews see Beehr \& Glazer, 2001; Glazer \& Beehr, 2005); no qualitative research has been done across cultures. Determining which stressors are most salient across different countries is relevant in order to develop prevention strategies and/or the resources needed to deal with the relevant stressors. Beehr, Jex, Stacy, and Murray (2000) suggested that assessing job-specific stressors (i.e., stressors that are conceptually and operationally specific to a job) is as important, if not more important than assessing generic stressors (i.e., stressors that can occur in any job that is embedded in a set of roles). In a meta-analytic study regarding stressors among U.S. nurses, Wheeler (1997b) depicted six stressor categories (i.e., leadership, organizational control, job-related, job image, reward system, human resources system related) relevant to nurses (in the U.K.).

Although functions that nurses perform are mostly invariant across cultures (Bureau of Labor Statistics, 2002/ 2003), education, training, status, equipment, and pay relative to other occupations within country and relative to nurses in other countries differ (Glazer \& Beehr, 2005). These circumstances would likely influence reports of different job-specific stressors and different levels of similar stressors. Beehr and Glazer (2005) noted that although there is quite a bit of information on general work-related role stressors, there is a great need for research on more jobspecific stressors. This is especially true with regards to nursing, which constitutes the largest health-care occupation (Bureau of Labor Statistics). Therefore, in this study we identify culture-specific (i.e., emic) and culture-general (i.e., etic) stressors faced by nurses in each of five countries (Hungary, Italy, Israel, U.K., and USA), without making a priori assumptions.

\footnotetext{
* Corresponding author. Tel.: +1 4089245639.

E-mail address: sharon.glazer@sjsu.edu (S. Glazer).

${ }^{1}$ Anett Gyurak is currently at the University of California, Berkeley.
} 


\subsection{Qualitative research on occupational stress}

Numerous problems are associated with quantitative survey methodology (the dominant type of data reported; Wheeler, 1997b, 1998a), including generic use of the word 'stress,' assessment of generic stressors, researcherimposed notions of relevant stressors and strains (Jex, Beehr, \& Roberts, 1992), and little cross-cultural validation (Glazer, 2002). First, as Jex et al. (1992) found, many scholars have erroneously used the generic word 'stress' to capture either stressors, strains, or both, however empirically they found that in the general population the word stress is most strongly associated with strains and anxiety. Hence, the meaning of stress to survey respondents is most likely what some occupational stress models define as strains, even though the researchers might have intended 'stress' to reflect stimuli or stressors. This confusion is so pervasive that it is practically impossible to compare research studies that stem from different interpretations of occupational stress (Jex et al., 1992; Wheeler, 1998b).

The problem concerning the definition of stress is compounded when traversing national boundaries. For example, Glazer (1999) noted that translating 'stress' into Hebrew could result in two words that, back-translated into English, would mean "pressure" (or stressors) or "strains/anxiety." This point relates back to the need for more research that clarifies causes of stress without researchers imposing the meaning for respondents. In this article, work-related stressors are defined as markers of the work itself, including aspects of the work environment (physical stressors, e.g., noise or heat), psychosocial environment (e.g., relations with co-workers and managers) or the job role (e.g., role ambiguity, and role conflict). Strains are conceptualized here as consequences of stressors that are appraised (Lazarus \& Folkman, 1984) as negative and something that exceeds or taxes the individual's coping resources (e.g., Jex \& Beehr, 1991). Strains can be physiological (e.g., elevated cortisol level, increased heart rate, blood pressure, cardiovascular symptoms, and back pain), psychological (e.g., depression, anxiety, and burnout), and/or behavioral (e.g., work place violence, and turnover) (Beehr \& Glazer, 2005). Strains can also become stressors if they are perceived to be taxing one's coping resources (Semmer, McGrath, \& Beehr, 2005).

Second, cross-cultural quantitative stress research has demonstrated differences in mean scores on stressors (e.g., Johns \& Xie, 1998; Miller et al., 2000; Schaufeli \& Janczur, 1994; Spector, Cooper, \& Aguilar-Vafaie, 2002; Spector et al., 2004). These studies further indicate that cross-cultural differences lie in the frequency at which aspects of the job are reported as stressful by incumbents in a particular nation (Lu, Tseng, \& Cooper, 1999; Siu \& Cooper, 1997; Wong, Chen, Yu, Lin, \& Cooper, 2002). Frequency of reported stressors across cultures might be due to the political and institutional settings in which these organizations are embedded (Glazer \& Beehr, 2005), which are impacted by government rules and policymaking (Hofstede, 1984). Therefore, it is important to consider the frequency at which stressors are mentioned within each culture. The frequency of mention could be indicative of its salience, however the majority of quantitative studies used an a priori set of stressors from which respondents chose. In order to uncover job relevant and truly salient stressors it is, therefore, important that respondents freely answer about the causes of their stress (Cooper, Dewe, \& O'Driscoll, 2001). After all, only the job incumbent really knows what stressors are most causal of her 'stress or anxiety.' The need for exploratory research that does not impose an a priori list of stressors is further warranted by a recent trend in studying stress across cultures (e.g., Baba, Galperin, \& Lituchy, 1999; Glazer \& Beehr, 2005). From a cross-cultural perspective, stress is likely a universal phenomenon, however what causes stress or anxiety among nurses in different cultures is still inconclusive (Glazer, 2002).

\subsection{Solution for cross-cultural stress research}

In this study, we content analyze reports of occupational stress among hospital nurses in five countries (Hungary, Israel, Italy, U.K., and USA). Free write-in responses to one open-ended question, "what causes you stress or anxiety" are analyzed. Although this procedure for a qualitative study is somewhat unorthodox, we argue that 'what is stress' to each individual has an almost automatic-like visceral response. It does not take very long to determine what causes one's own stress or anxiety and therefore respondents are likely able to recount job stressors and strains without indepth interview. Furthermore, which stressors lead to strains is different for each individual in different circumstances (Semmer et al., 2005); however, consistency of stressor-reports in various cultural contexts would suggest a

\footnotetext{
${ }^{2}$ The singular pronoun and possessive for a nurse will be in the feminine form of 'she' or 'her" because $90.2 \%$ of the nurses in the present study are female.
} 
professional culture influence, more than national culture influence. Thus, a content analysis, done with a relatively large dataset, would likely demonstrate the importance of assessing work-related stressors that are particularly relevant in a given national context (in addition to the current trend of assessing generic work-related stressors). Generic stressors are generally studied in order to inform theory and context-specific stressors are examined in order to discover root causes of strain in a given situation. The goal is to then utilize large amounts of data collected this way for purposes of developing stress prevention programs (Quick, Quick, \& Nelson, 1998). Through this study we hope to discover what aspects of "stress" are likely emics (i.e., culture-specific) and what aspects are likely etics (i.e., generalizable across cultures) in the nursing profession.

\subsection{Classifying job-specific stressors to nursing stressors across cultures}

For the study's classification system of stressors, we drew heavily on Beehr and Newman's (1978) theory of occupational stress, Jex and Beehr's (1991) classification of stressors and strains, and Wheeler's (1997b) meta-analysis of stressors related to the nursing profession. We do not attempt to impose theoretical stress models, because "models make assumptions about mechanisms and relationships" and our goal is to discover the conditions that give rise to the phenomenon in question (Semmer et al., 2005, p. 3). Jex and Beehr's theory include two types of generic stressor categories, individual stressors and organizational stressors, and three types of strains (i.e., psychological, physical, and behavioral) that over time can become stressors themselves. Most relevant to this study is the stressor categories. Individual level stressors included role stressors, job control, situational variables, workload, shiftwork, other workers that the individual interacts with, as well as strains (psychological, physical, and behavioral) that can become job stressors. Strains can become stressors because of the cyclical nature of stress (Semmer et al., 2005). For example, a nurse chooses to ignore the call of a difficult patient, but lack of attention to the patient (i.e., the strain) becomes the situation that creates further strain (such as forgetting to administer medication to the patient). Among organizational stressors, Jex and Beehr (1991) reviewed two more stressors, budgetary cuts and layoffs.

Wheeler (1997b), however, listed 34 potential stressors that he organized under 6 larger categories. These six categories are leadership, organizational control, job-related, job image, reward system, human resources system related. The leadership category reflects on leader communication and direction, relationship with the leader, leader style, utilization of staff, and concern for staff. Organizational processes included 'negative or punitive reward systems' (i.e., organization rewarding quantity but not quality, general value conflict between the nurse's personal value and the organization's), 'lack of staff,' 'rules and administrative requirements' (e.g., unnecessary paperwork Wheeler's, 1997b), and both 'intra-organizational' and 'governmental regulations.' The human resources category included 'lack of training and development,' and 'poor skill mix of staff.' A job-related stressor that Wheeler reported on was 'time pressure on the job.' Job image referred to the prevailing perception of the nursing profession in the society as perceived by the respondent. Finally, reward system was operationalized in terms of distribution and perceived fairness of the process of allocation of incentives, benefits, and organizational rewards.

Although these taxonomies serve as a foundation that guides the creation of our categories, a problem with Jex and Beehr's (1991) theory of occupational stress is that the stressors suggested for study are rather generic and the problem with Wheeler's (1997b) study is that the stress categories were derived from a literature review and not directly obtained from nurses' open responses. In this study, therefore, we intend to address these prior limitations by content analyzing nurses' reported stressors that are most salient, which will inevitably be more specific for nurses than other occupations.

\subsection{Hypotheses}

Wheeler's (1997a, 1997b, 1998a, 1998b) reviews of English language literature were used as one of the bases for developing our study questions. However, because of the paucity of cross-cultural research on occupational stress, it is difficult to develop hypotheses about etic aspects of stress. Moreover, hypotheses of etics are in essence hypotheses of similarities and trying to determine that there are no differences is akin to trying to provide evidence in support of a null hypothesis.

$\mathbf{H}_{1}$. Based on Wheeler's (1997b, 1998a) findings quantitative workload is expected to emerge as an etic stressor in the nursing profession. 
H2. Based on Wheeler's (1997b, 1998a) findings management or leadership problems are expected to be frequently mentioned as a source of stress and anxiety in each of the five countries.

Due to lack of empirical research of country-specific differences with regard to occupational stress experience, it is similarly challenging to develop sound hypotheses. Thus, personal experiences by both authors' having lived in Hungary during the time of data collection in 1997 and factual information about the countries were utilized in trying to formulate hypotheses regarding emic differences in nurses' reports of causes of stress or anxiety and contextualize the findings.

The health-care system in Hungary is owned and run by the government. After the end of socialism, the government of Hungary was left with large debts and this liability put state owned organizations in a very difficult financial situation. Hospitals saw their funding cut several times in the ensuing years and this shortage continues to pervade the system even today. According to the World Bank (n.d.), Hungarian per capita health-care expenditure was about U.S.\$ 496 in 2002. Furthermore, the United States ranked first in such expenditures, spending U.S.\$5274 per capita, followed by the U.K., spending U.S.\$2031, Italy, spending U.S.\$1737, and Israel, spending U.S.\$1496 per capita. The rank-order and proportion of health-care expenditures in relation to other expenditures have not changed from 2002 to 2004 (for which there is the latest data; OECD, 2007). In fact, Hungary has experienced a great deal of hospital closures, little change in salaries, and worse budgetary problems than any other European Union country (Gati, 2007a; Reuters, 2007). Therefore, it is hypothesized that:

$\mathbf{H}_{3}$. Hungarian nurses will report problems associated with lack of resources (i.e., supplies and budgetary constraints) more frequently than nurses in the other countries.

Also, four countries (Hungary, Israel, Italy, and U.K.) have a health-care system that is, at least, partially government run in contrast to the largely privately managed U.S. health-care system. It is likely that the market and profit oriented nature of the U.S. health-care system, one that tries to maximize earnings, goes against the inherently patient-oriented nature of the nursing profession thereby creating a misfit between the rewards allocated by the organization and the values of nurses. This misfit between person and environment might lead to anxiety (French, Caplan, \& Van Harrison, 1982). Prevalence of the misfit would be noted by frequency to which nurses in one country, more than others, report 'reward structure' as a source of stress.

$\mathbf{H}_{4}$. U.S. nurses will report negative or punitive reward or appraisal systems as a cause of stress on the job because of the market managed health-care system in the USA.

In addition to these hypotheses, the goal of the study is to further explore relevant other emic or etic stressors to the nursing profession within and across these five countries. This study is mostly exploratory in nature. Few $a$ priori hypotheses regarding which stressors are expected to be reported most frequently are posed, because no research to date indicates how respondents will perceive the concept of "causes of stress or anxiety" across different countries nor does any research suggest differences in personal accounts of "causes of stress or anxiety." Thus, the central hypothesis is that there will be many similar stressors reported in each country, yet there will also be unique stressors or demands (i.e., different frequency of reports of stressors across countries) (Bhagat et al., 1994; Laungani, 1993).

\section{Methods}

\subsection{Participants}

The study's sample consisted of 2144 nurses working in 19 hospitals in Budapest, Hungary, northern Israel, northern Italy, London, U.K., and the Baltimore area of Maryland in USA. Out of 2144 respondents 1442 (139 of whom were male and 85 of whom did not report sex), or $68.2 \%$ answered the qualitative portion of the questionnaire. More demographics and employment variables of the sample are presented in Table 1. Chi-square analyses and $t$-tests (with Bonferroni adjustment $p<0.001$ significance level) are performed on those who answered the qualitative question vs. those who did not answer the qualitative questions on sex, job title, employment status, supervisory role, age, years in nursing, and average number of patients in unit. Note that chi-square analyses are corrected for base rates therefore, analyses are on expected counts. The only difference that emerged was that nurses in the U.K. who provided 
Table 1

Demographic and work characteristics information of the sample by country

\begin{tabular}{|c|c|c|c|c|c|c|c|c|c|c|}
\hline & \multicolumn{2}{|c|}{$\begin{array}{l}\text { Hungary } \\
(N=626)\end{array}$} & \multicolumn{2}{|c|}{$\begin{array}{l}\text { Israel } \\
(N=506)\end{array}$} & \multicolumn{2}{|c|}{$\begin{array}{l}\text { Italy } \\
(N=430)\end{array}$} & \multicolumn{2}{|c|}{$\begin{array}{l}\text { United Kingdom } \\
(N=197)\end{array}$} & \multicolumn{2}{|c|}{$\begin{array}{l}\text { United States } \\
(N=355)\end{array}$} \\
\hline & QA & NQA & QA & NQA & QA & NQA & QA & NQA & QA & NQA \\
\hline Respondent & 433 & 193 & 258 & 248 & 289 & 141 & 178 & 19 & 284 & 71 \\
\hline Respondent (\%) & 69.2 & 30.8 & 51 & 49 & 67.2 & 32.8 & 90.4 & 9.6 & 20 & 80 \\
\hline Female $(\%)$ & 68.2 & 29.8 & 43.9 & 41.2 & 52.8 & 22.7 & 12 & 2.6 & 77.5 & 18.5 \\
\hline Male (\%) & 1.7 & 0.3 & 7.8 & 7.2 & 14.5 & 10.1 & 79.2 & 6.3 & 2.8 & 1.1 \\
\hline Reg. nurse (\%) & 23.1 & 12.9 & 41.9 & 41.3 & 22.4 & 12.2 & 59.9 & 7 & 43.7 & 10.6 \\
\hline Full time (\%) & 65.4 & 25.9 & 30 & 32.3 & 64 & 29.9 & 86.6 & 9.1 & 64.5 & 14.7 \\
\hline Supervisor (\%) & 36.2 & 11.4 & 31.1 & 33.8 & 23.1 & 10.3 & 84.6 & 7.2 & 45.7 & 7.6 \\
\hline Age (years) & 34.0 & 36.0 & 38.9 & 39.0 & 32.6 & 33.0 & 34.4 & 36.4 & 41.4 & 41.0 \\
\hline Years in nursing & 13.5 & 15.6 & 14.5 & 15.7 & 10.6 & 10.4 & 13.7 & 15.3 & 16.7 & 15.9 \\
\hline Years in unit & 9.8 & 13.0 & 7.5 & 8.5 & 5.9 & 6.4 & 4.9 & 9.0 & 8.1 & 8.2 \\
\hline Ave. num. of patients in unit & 28.8 & 30.6 & 19.2 & 20.8 & 24.9 & 21.7 & 33.8 & 28.1 & 29.0 & 24.5 \\
\hline
\end{tabular}

QA: respondents who answered the qualitative question; NQA: respondents who did not answer the qualitative question.

a qualitative answer spent an average of 4.9 years in their unit compared to 6.6 years for those who did not provide a qualitative answer $F(2,191)=11.5, p<0.001$.

Because numerous participants mentioned more than one unique stressor in their responses, the dataset actually consisted of 3172 unique incidences of stressors. In other words, each respondent provided an average of 2.19 unique responses. Some provided just one and others provided as many as five. Omnibus ANOVA indicated a main effect difference between the five countries on how many stressors on average nurses reported $(F(4,1427)=32.5, p<0.05)$. On average, Hungarian nurses reported 1.57 stressors, Israeli nurses reported 2.14 stressors, Italian nurses reported 1.87 stressors, U.K. nurses reported 2.5 stressors, and U.S. nurses reported 2.07 unique stressors per respondent. We consider these differences to be indicative of emic differences, therefore the number of stressors reported by the nurses in each country is not controlled.

\subsection{Procedures}

\subsubsection{Data collection}

Data were collected from nurses in three to five hospitals in each country to minimize the influence of organization specific processes. The Chief Nurse in each country (with the exception of one hospital in Italy) was approached by the first author and asked to have their nurses participate in the completion of an anonymous survey. Hospital management agreed to data collection methodology before nurses were approached. No hospital had access to completed surveys or raw data. In the Hungarian, Italian, and U.K. and U.S. English versions of the survey, the open-ended question analyzed for the present study was the last question on the last page of a 10-page quantitative paper-pencil survey, whereas it was the last question on the second page of a 10-page survey for the Israeli version.

Data in Hungary, Italy, U.K., and the U.S. were collected from April 1997 to January 1998. In Israel data were collected between May and July 1994. Although these data have been obtained about a decade ago, there have been minimal changes in health-care delivery and expenditures in these countries (Gati, 2007a; OECD, 2007; Rosen, 2003). Health-care reforms, like national and organizational cultures, take time to impact all aspects of the health-care industry. The greatest reforms are taking place in Hungary and they are structural reforms, as opposed to job design reforms (Gati, 2007a), which would likely have the greatest impact on reports of causes of stress and anxiety (Quick et al., 1998). For example, nurses still earn meager salaries in relation to cost of living in Hungary (Gati, 2007b) and staff shortages (i.e., lack of staff) are still a big problem in U.K. hospitals (Woolf, 2007). Although there has been some privatization of health-care, most hospitals in Hungary are still government run (Gati, 2007a). Private hospitals are visited only by the few who can afford it (typically international sojourners). One year after data collection in Israel, a new policy for health insurance coverage was introduced there. In addition, nurses in Israel have been playing an increasingly larger role in the delivery of clinical health-care to chronically ill patients, though the number of nurses per 1000 inhabitants is still lower than the EU average (Rosen, 2003). 
The open-ended question asked was "what causes you the most stress or anxiety on your job?" Although the question utilizes the word 'stress,' it is qualified with anxiety in order to provoke responses of stressors. At the same time, nurses can impose their own understanding of stress with the open format. In other words, asking this question allows for free-interpretation of stress, though still guiding toward the definition of a strain with the use of the word "anxiety." Jex et al. (1992) would probably argue that the use of 'anxiety' as a qualifier is not far from the general populations' interpretation, as 'stress' for the general population usually refers to strain.

Handwritten responses were first transcribed as written in the main language of the country, then the Hungarian, Italian, and Hebrew language responses were translated and transcribed into English by bilingual speakers. All three translators were born and raised in their respective countries. At the time of the data analysis, the Hungarian translator (second author) was a graduate student of Industrial/Organizational psychology in the United States, the Italian translator was a software professional working in the Unites States, and the Hebrew translator was the Hebrew language director of a private K-12 day school in the USA. Both the Hebrew and Italian language translators were paid for their services.

\subsection{Data analysis}

Due to the nature of the data utilized for the present study, content analysis was the method chosen to categorize and explicate themes that were common in responses (Krippendorf, 1980). The classification procedures lead to quantifiable data that were subjected to statistical analysis. The first phase of content analysis required development of a categorization scheme. Responses were first reviewed to get a general sense of the nature of the data. On the basis of Wheeler's (1997a) meta-analysis of nurse work-stress literature and Jex and Beehr's (1991) model of occupational stress, an initial categorization scheme was developed. These taxonomies guided the categories developed, but are not completely consistent with them (e.g., 'budgetary cuts' was grouped under job-related stressors by Wheeler, 1997b, but we felt it belonged under the organizational stressors category).

The categorization taxonomy (presented in Table 2) consisted of 33 specific categories (e.g., stress caused by leadership style, rigid organizational policies, work overload, staff shortage) with five overarching domains. These domains are (1) leadership induced stressors, (2) organizational stressors, (3) job-related stressors, (4) strains, and (5) miscellaneous stressors. After the initial categorization scheme and definition of categories, the taxonomy was refined with the help of two coders and the first author. For training purposes, initially $10 \%$ of responses were randomly selected and placed into the five domains (three of which are stressor categories) and 33 subcategories. ${ }^{3}$

The unit of categorization was each unique response from each participant. That is, if a participant provided multiple unique responses, each response would be categorized. However, if a nurse wrote the same stressor twice in her answer (e.g., high workload and too much work), it was coded only once; this ensured that elaboration, clarification, or definition of the response was not coded twice. After 13 hours of training, during which the two coders and second author jointly categorized a randomly selected subset of answers, the actual categorization began.

The two coders ${ }^{4}$ manually coded responses using Wordstat 4.0 Beta version content analysis software. The software was used to aid categorization by making it easy to assign categories using a highlight-and-click technique. Wordstat 4.0 is a software program for content analyzing qualitative data. Raw data are displayed on a computer monitor with the 'to-be-coded' responses along side the coding taxonomy. During coding, coders would highlight a response (unique stressor within one answer) by depressing the left button of the mouse and then clicking on the category to which they felt the item belonged. The computer logged the selection automatically and stored it on the hard-drive in MS Excel worksheet format. These files were later retrieved and the categorizations of the two coders were compared. Coding disagreements between the two coders were resolved under the second author's supervision. Categorization of data was completed in January 2004 over a period of two weeks. During this time the two coders worked independently and met with the second author jointly twice a week. These meetings served two purposes: (1) to keep

\footnotetext{
${ }^{3}$ Randomization of the dataset was performed in MS Excel software by assigning a random number to an answer. Then data were sorted by the random number to 'shuffle' the answers. This procedure ensured that a true random sample is drawn from the response pool. Following this with the above-described procedure of randomization, another $5 \%$ of the answers were pulled out and categorized by the two coders under the second author's supervision.

${ }^{4}$ One of the coders was a first year graduate student of Industrial/Organizational psychology and the other coder was a postbaccalaureate psychology student at the same university. Both students were in a graduate level course in occupational stress when the coding began.
} 
Table 2

Categorization taxonomy

\begin{tabular}{ll}
\hline Category name & Category description \\
\hline $\begin{array}{l}\text { Leadership induced stressors } \\
\text { Leadership }\end{array}$ & $\begin{array}{l}\text { Autocratic leadership style of supervisors or others higher up in the hierarchy. } \\
\text { Complaint about the behavior of the supervisor (i.e., chief nurse, physician), for example } \\
\text { being condescending or rude. Specific mention of unsatisfying relationship with supervisors. } \\
\text { Lack of support and lack of respect from supervisor. Supervisor or other leaders of the } \\
\text { organization do not show concern for the welfare of the person }\end{array}$ \\
$\begin{array}{l}\text { Inadequate direction from supervisors, unclear instructions. Different from role } \\
\text { ambiguity where the subjective experience of unclear expectations are the main } \\
\text { themes. Problems with the organizational structure (e.g., nurse }\end{array}$ \\
$\begin{array}{l}\text { tirection from the supervisors } \\
\text { reports to multiple supervisors) } \\
\text { Disagreements, differing opinions with regards to instructions from the supervisor } \\
\text { or someone from above the nurse in the hierarchy }\end{array}$ \\
$\begin{array}{l}\text { Differing opinions and } \\
\text { disagreement }\end{array}$
\end{tabular}

Organizational stressors

Poor organizational climate

Low salary

Negative or punitive reward and appraisal system

Resources

Lack of staff

Skillset of staff

Administrative, extramural

Rigid policies, no say in change

Job role ambiguity

Rules and administrative, intramural

Development and training

Under-utilization of staff/resources

(Conflict with) co-workers

Disorganization

Environment, surroundings

Job-related stressors

Interaction with patients and relatives

Type of patients

Responsibility

Quantitative workload

Qualitative workload

Death and dying
Sense of everybody being dissatisfied, low job morale, negative atmosphere at work Poor and inadequate salary or monetary compensation, unable to afford necessities. (This is different from lack of hospital funds)

Inadequate organizational rewards, the way rewards are administered, the way they are tied to performance, the way performance is appraised (e.g., system rewards volume, not quality). Conflict between personal values and hospital's values. Misdirected rewards due to how the reward and appraisal system is set up

Inadequate resources, lack of information sharing between departments, lack of funds, lack of supplies, lack of equipment or broken equipment. Resources not available when needed

Problems associated with scheduling, staff shortage, substituting for co-workers Problems with inadequate skillset of the staff (e.g., agency and temporary workers) Problems with complying with governmental rules and regulations or with regulations that are imposed on the nurse from an outside institution Organizational policies are difficult to influence, inflexible. Little say in policy formation, no one listens, or asks. Decisions are made above one's head. Difficult to induce change

Unclear job roles and expectations, the nurse does not know what is expected of her. The fact of not knowing what to do, but different from qualitative overload where the nurse is not trained well enough to complete the tasks, whereas job role ambiguity implies unclear expectations

Rules that do not make sense (e.g., unnecessary paperwork, tasks that are not part of caring for patients). Fast changing rules, complying with rules that are imposed upon the nurse

Poor or no training, and developmental opportunities

Inadequate utilization of staff or resources. Not knowing what things are there for and not using resources adequately (e.g., improper use of common areas)

Personality of co-workers, behavior of co-workers. Conflict resolutions with co-workers Complaint about disorganization, lack of order

Inadequate physical surroundings (e.g., heat, dirt, noise, hospital layout, and safety)

Problems interacting with patients or relatives, delivering news, requests, and questions

Type of patients in terms of condition (e.g., HIV positive, cardiac), personality, race, and age Being required to make a decision or to make a judgment call (e.g., make decisions that affect someone's life)

Excessive workload demands that the person cannot meet. Long work hours, excessive patient load. Quantitative overload is defined when there are too many things do in the allotted time. Competing priorities

Demands that exceed the person's ability (e.g., task is too complex, too demanding). Or qualitative underload, when the tasks that the nurse is required to complete are too simple, not challenging enough

Process of dying, assisting the dead, death, resuscitation, and taking people off of life support 
Table 2 (Continued)

\begin{tabular}{ll}
\hline Category name & Category description \\
\hline Time pressure & $\begin{array}{l}\text { Sense of being under time pressure, sense of not being able to have a break, being on call } \\
\text { Subjective feelings of constant readiness, preparedness because something } \\
\text { might happen. Does not necessarily have to mention the looming threat, } \\
\text { it is enough if the sense of readiness is there }\end{array}$ \\
& $\begin{array}{l}\text { Problems associated with providing services to people and caring for people } \\
\text { Working shifts, allocating medication, drawing blood, and washing the } \\
\text { patients, but not resuscitation }\end{array}$ \\
Certain types of tasks & $\begin{array}{l}\text { Fulfilling expectations, pleasing and meeting needs of patients, patients } \\
\text { families, and physicians }\end{array}$ \\
Fulfilling expectations & Status in society, profession is not well respected, work-family conflict \\
Miscellaneous stressors & \\
Strains & Feelings of giving up, helplessness, anxiety, apathy, dissatisfaction, fatigue, \\
Psychological & listlessness, frustration, dejection \\
Decreased effort, provision of poorer patient care, intention to leave \\
Behavioral & Job-related physical complaints (e.g., headaches, backaches) \\
\hline Physical symptoms &
\end{tabular}

the coding taxonomy and definitions closely aligned to prevent category shift, as it is not unexpected that idiosyncratic interpretation of taxonomy emerges if there is no contact between the coders (Krippendorf, 1980), and (2) to resolve coding disagreements. During the meetings, coding disagreements were discussed and responses were re-categorized under the category that was mutually accepted by both coders.

One hundred and sixty two responses out of 1442 answers were deemed not to contain enough information to categorize unanimously. Some of these segments were mentions of names of individuals with not enough information to determine the relationship of the respondent to the person, or consisted of illegible words that made the interpretation of the segment impossible.

Initial inter-rater agreement was calculated using the Kappa statistics, a widely used index of coder agreement of classification statistics that corrects for chance agreement between the two coders. Agreement between the two coders was 0.79 which constitutes a strong agreement (Fleiss, 1981). For each unit categorized, chance uncorrected agreement ranged between 73.3 and $86.3 \%$ throughout the 2 weeks of coding between the two coders. Chance uncorrected agreement index provides a rough measure of agreement. At the meetings, all coding disagreements were discussed and resolved and $100 \%$ agreement was reached. Statistical analyses were performed on this dataset.

Table 2 provides a complete list of stressors and strains along with the definitions used in the study. The leadership induced stressors category included three subcategories, organizational stressors consisted of 15 stressors, and jobrelated stressors consisted of 11 subcategories. In addition, a fourth category included miscellaneous stressors and a fifth category reflected strains.

In order to examine Hypothesis 1, stressors within each country were rank ordered and the order of each stressor was examined. If Hypothesis 1 is supported, quantitative workload would rank as the most frequently reported stressor in each of the five countries. However, because rank ordering is a relatively crude way of deriving etics of occupational stress experience we follow with an omnibus Chi-square analysis. Analogous to ANOVA approaches, omnibus Chisquare analysis is appropriate for categorical data and corrects for between-country differences in terms of the percentage frequency of reports of a given stressor. If there are no between-country differences on quantitative workload as a stressor, the omnibus Chi-square analysis will not be significant. However, in the event there are between-country differences, the omnibus Chi-square analysis will be significant and will need to be followed by pairwise comparisons in order to determine which countries differ significantly from each other.

The Chi-square analysis procedure is used for testing the other hypotheses too, with few modifications. In testing Hypotheses 3 and 4, we correct for multiple comparisons that increase the chance of Type 1 error, by employing a Bonferroni adjusted $(p<0.01)$ omnibus Chi-square test. Significant omnibus analyses are followed by a series of post hoc pair-wise comparisons on stressors that emerge as significantly different. In these analyses the significance level is adjusted further $(p<0.001)$.

Finally, comparisons of the reported stressors are aimed at deriving etic and emic characteristics of occupational stress experience and thus purely exploratory. In these analyses we use a series of Bonferroni adjusted $(p<0.01)$ Chi- 
square statistics followed by pair-wise comparisons between countries on all stressors that are not tested in relation to specific hypotheses.

\section{Results}

\subsection{Hypothesis 1: quantitative workload as etic stressor in nursing profession}

\subsubsection{Rank ordering analysis}

Hypothesis 1 was partially supported (see Table 3). 'Quantitative workload' was frequently reported as a stressor in each of the countries. More specifically, of the 33 stressor categories, 'workload' was rank ordered as one of the top 10 most frequently reported sources of stress among nurses in each of the five countries (see Table 3 for a list of the top 10 stressors mentioned in each country). One nurse from Israel wrote, “... large number of patients more than the hospital can handle, hallway is full of patients waiting ...."

\subsubsection{Chi-square analysis}

An omnibus Chi-square analysis on 'quantitative workload' indicated that there were between-country differences in the extent to which work overload was stressful in the five countries $\left(\chi^{2}(4,1428)=46.85, p<0.001\right)$. To explore these differences, a series of pair-wise Chi-square tests were performed. According to the results, quantitative workload was reported significantly more often by nurses in Israel $(33.3 \%)$ than nurses in Hungary $(12.8 \%$; $\left.\chi^{2}(1,679)=41.1, p<0.001\right)$, and in the U.K. $\left(19.1 \% ; \chi^{2}(1,540)=10.7, p<0.001\right)$. Between-country differences also emerged between Italian $(22.8 \%)$ and Hungarian nurses $\left(\chi^{2}(1,710)=12.23, p<0.001\right)$, and Hungarian and U.S. nurses $\left(28.4 \% ; \chi^{2}(1,703)=26.44, p<0.001\right)$. Together, results of the rank ordering and Chi-square analyses suggest that Hypothesis 1 is partially supported. Although work overload appears to be among the top 10 stressors for nurses in each country, and therefore it can be considered an etic stressor, it is reported more frequently in Israel and the U.S. than any other country.

\subsection{Hypothesis 2: leadership problems as stressor across countries}

Hypothesis 2 was partially supported. Although 'Leadership' was among the 10 most frequently mentioned stressors in all five countries (Table 3), omnibus post hoc comparisons indicated between-country differences on the frequency of leadership stressor. Results of the omnibus Chi-square test showed that 'leadership' (described by personality and behavior of the leader) differed significantly between countries $\left(\chi^{2}(4,1428)=42.47, p<0.001\right)$. Post hoc comparisons indicated that there were significant differences between nurses in Hungary $(13.3 \%)$ and the U.K. $\left(28.7 \% ; \chi^{2}(1,599)=20.09, p<0.001\right)$, Hungary and the U.S. $\left(24.8 \% ; \chi^{2}(1,703)=15.24, p<0.001\right)$, and Israel $(9.3 \%)$ and the U.K. $\left(\chi^{2}(1,436)=27.69, p<0.001\right)$, U.S. $\left(\chi^{2}(1,540)=22.57, p<0.001\right)$. Nurses in the U.K. and the USA mentioned this stressor significantly more frequently than Israeli and Hungarian nurses. However, the frequency

Table 3

Rank order of the first 10 stressors according to the highest percentage in each country

\begin{tabular}{|c|c|c|c|c|c|}
\hline Rank & Hungary & Israel & Italy & U.K. & U.S. \\
\hline $1 \mathrm{st}$ & Lack of resources & Quantitative workload & Lack of staff & Lack of staff & Lack of staff \\
\hline 2nd & Death and dying & Lack of staff & Quantitative workload & Leadership & Quantitative workload \\
\hline $3 \mathrm{rd}$ & Certain type of tasks & Type of patients & Leadership & Co-workers & Leadership \\
\hline 4 th & Leadership & Certain type of tasks & Type of patients & Quantitative workload & Co-workers \\
\hline 5 th & Staff shortage & Lack of resources & Certain type of tasks & Time pressure & Certain type of tasks \\
\hline 6th & Quantitative workload & $\begin{array}{l}\text { Interaction with patients } \\
\text { and relatives }\end{array}$ & Co-workers & Type of patients & Type of patients \\
\hline 7th & Type of patients & Co-workers & Lack of resources & Lack of resources & Time pressure \\
\hline 8th & Co-workers & Leadership & Time pressure & Skillset of staff & Lack of resources \\
\hline 9th & Psychological & Death and dying & $\begin{array}{l}\text { Interaction with patients } \\
\text { and relatives }\end{array}$ & Certain type of tasks & Miscellaneous stressors \\
\hline 10th & Inadequate communication & Skillset of staff & Disorganization & $\begin{array}{l}\text { Interaction with patients } \\
\text { and relatives }\end{array}$ & Negative rewards \\
\hline
\end{tabular}


between Hungary and Israel was not significantly different therefore the hypotheses is partially supported. Leadership stressor is mentioned equally frequently in two of the five countries.

\subsection{Hypothesis 3: lack of resources as stressor for Hungarian nurses more than nurses in other countries}

Hypothesis 3 was partially supported as 'Lack of resources' (monetary and supply) was an often mentioned (top 10) stressor across the countries (11.8-20.19\% of the nurses mentioned it, see Table 3 and Fig. 2). Further, there were no main differences between countries at the adjusted significance level, though it appeared to be the most pervasive in Hungary (20.19\%). One example of this stressor was written by a nurse in Italy. She complained "we are unable to send patients back to the Recovery Units because there are no beds available." Another example is from Israel: “. . . there are not even available beds, or when you need certain equipment when reviving a person and it is not available."

\subsection{Hypothesis 4: appraisal system as stressor for U.S. nurses more than nurses in other countries}

Hypothesis 4 was partially supported (see Fig. 2). Omnibus Chi-square statistics indicated significant differences across countries on "negative or punitive reward or appraisal system" as a stressor $\left(\chi^{2}(4,1428)=28.6, p<0.001\right)$. Post hoc analyses revealed significant differences between nurses in the U.S. and Hungary $\left(\chi^{2}(1,703)=15.3\right.$, $p<0.001)$, and Israel and the U.S. $\left(\chi^{2}(1,540)=10.45, p<0.001\right)$. In the U.S., $4.96 \%$ of the nurses said that the way their work is rewarded (rewards quantity rather than quality, speed than quality) is stressful to them, whereas $0.48 \%$ of the sample in Hungary, and $0.39 \%$ of the nurses in Israel reported this as a stressful aspect of their job. A poignant example comes from a U.S. nurse who wrote "although I feel very strongly about the hospital, I do not feel that it values me. The mission and values of the hospital have changed, and it is much more focused on money, not on the value of its staff." No other between-country differences emerged.

\subsection{Exploratory analyses of other stressors}

Frequencies of reported stressors are provided in Figs. 1-3, as well as Table 4.

\subsubsection{Leadership induced stressors}

For leadership induced stressors (Fig. 1) 'inadequate communication and directions from the supervisor' and 'leadership (style and supervisor's behavior)' emerged as significantly different across countries. "Differing opinions and disagreement" was reported by $0.24 \%$ of the Hungarian respondents, but not by nurses in any other nation. Communication from the supervisor was found to be different between countries $\left(\chi^{2}(4,1428)=21.35, p<0.001\right)$. Hungarian nurses raised the problem of supervisory communication most often ( $4.9 \%$ of the sample). As an example of supervisory communication as a source of occupational stress, one Hungarian nurse wrote, "doctors give contradictory orders on the same problem."

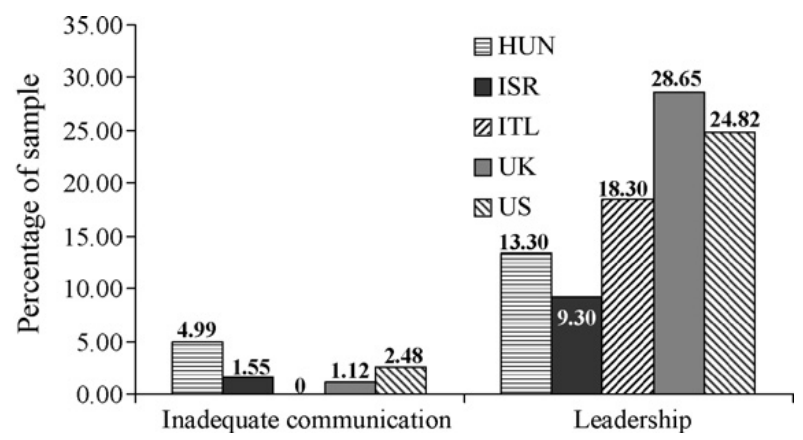

Fig. 1. Country profiles for major leadership induced stressors. Note. Numbers above bars represent percent of within country sample reporting the stressor. A significant difference on "Inadequate Communication" was between Hungary and Italy, $p<0.01$, and on "Leadership" differences were between Hungary and the U.K., Hungary and the U.S., Israel and the U.K., Israel and the U.S., $p<0.01$. 


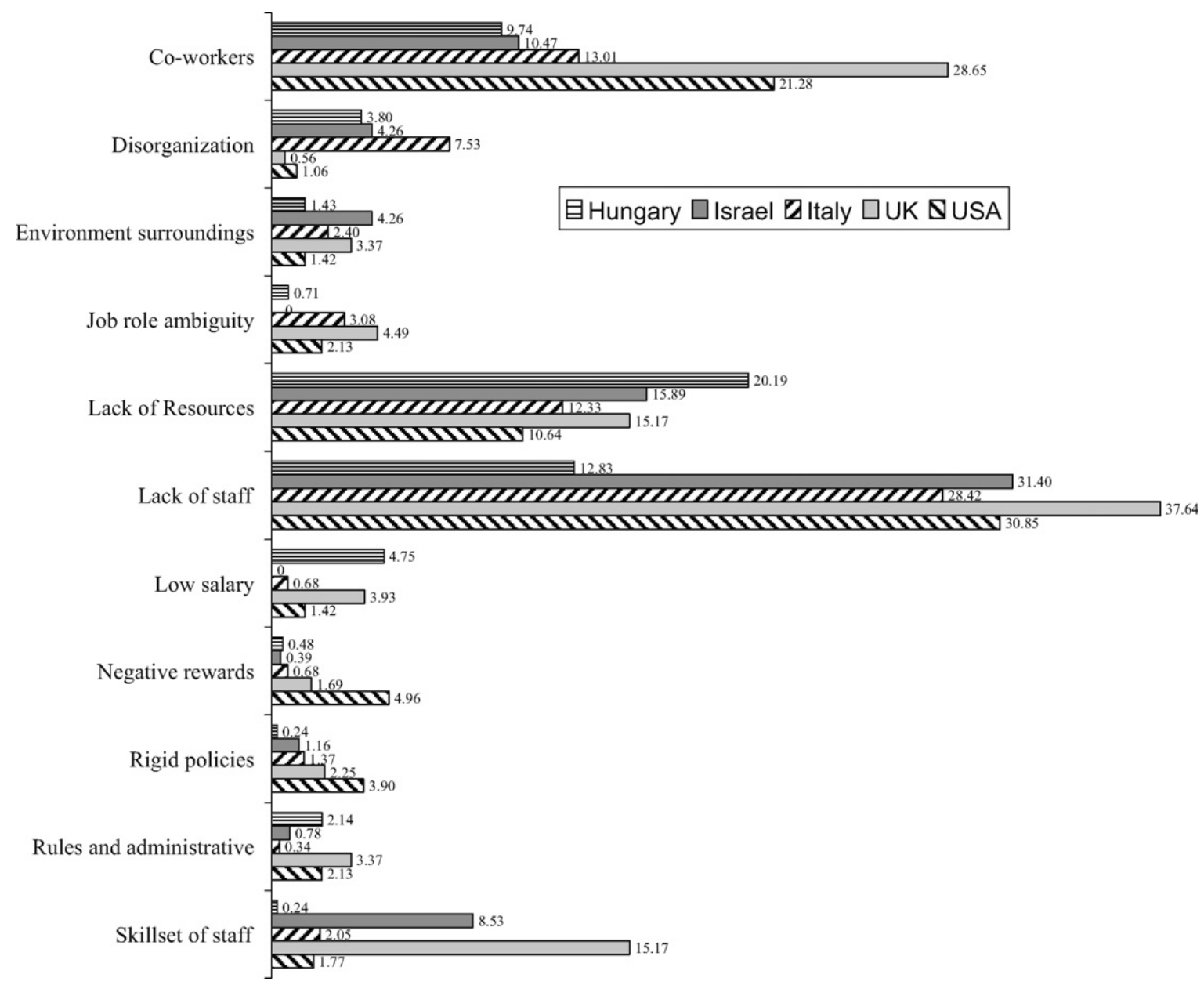

Fig. 2. Country profiles for major organizational stressors. Note. Significant differences $(p<0.01)$ between countries were found on the following variables: (1) "Co-workers"-Hungary and U.K.; Hungary and U.S.; Israel and U.K.; Israel and U.S.; Italy and U.K. (2) "Disorganization"-Italy and U.K.; Italy and U.S. (3) "Job role ambiguity"--Israel and U.K. (4) "Lack of resources"- -Hungary and U.S. (5) "Lack of staff" - Hungary and Israel; Hungary and Italy; Hungary and U.K.; Hungary and U.S. (6) "Low salary"- -Hungary and Israel; Hungary and Italy; Israel and U.K. (7) "Negative reward"-Hungary and U.S.; Israel and U.S. (8) "Skillset of staff" - Hungary and Israel; Hungary and U.K.; Israel and Italy; Israel and U.S.; Italy and U.K.

\subsubsection{Organizational stressors}

Among organizational stressors (Fig. 2), low salary was significantly different across the countries $\left(\chi^{2}(4,1428)=23.62, p<0.001\right)$. According to the pair-wise comparisons, Hungarian nurses reported low salary as a stressor more frequently $(4.75 \%)$ than Israeli nurses $\left(0 \% ; \chi^{2}(1,679)=12.63, p<0.001\right)$, and Italian nurses $\left(0.68 \% ; \chi^{2}(1,710)=9.4, p<0.001\right)$. Furthermore, omnibus Chi-square analysis was significant on 'Lack of staff/staff shortages' as a source of stress $\left(\chi^{2}(4,1428)=58.9, p<0.001\right)$. Hungarian nurses reported a shortage of staff significantly less often (12.83\%) than nurses in the other countries. Pair-wise comparisons' significant differences were between Hungary and Israel $\left(31.4 \% ; \chi^{2}(1,679)=34.63, p<0.001\right)$, Hungary and Italy $(28.7 \%$; $\left.\chi^{2}(1,710)=27.8, p<0.001\right)$, Hungary and the U.K. $\left(37.64 \% ; \chi^{2}(1,599)=47.79, p<0.001\right)$, and Hungary and the U.S. $\left(30.85 \% ; \chi^{2}(1,703)=34.22, p<0.001\right)$. Furthermore, as shown in Table 3, of all the stressors mentioned within country, Italian, U.S., and U.K. nurses mentioned staff shortage most often of all stressors, for Israeli nurses it was the second most frequently mentioned stressor, and for Hungarian nurses it was rank ordered in the 5th position. In the U.K., this problem was coupled with problems regarding the skillset of available staff $(15.17 \%)$. Israeli nurses also reported a problem with skillset, making it one of the top 10 stressors for Israeli nurses, but it was significantly lower in frequency (8.53\%) than for U.K. nurses. Nurses in the other countries did not report this as a prevalent issue.

Conflict with 'co-workers' was an often mentioned source of stress at the workplace across the board $(9.74 \%$ in Hungary, $10.47 \%$ in Israel, $12.8 \%$ in Italy, $28.65 \%$ in the U.K., and $21.28 \%$ in the U.S.; $\left(\chi^{2}(4,1428)=48.77\right.$, 


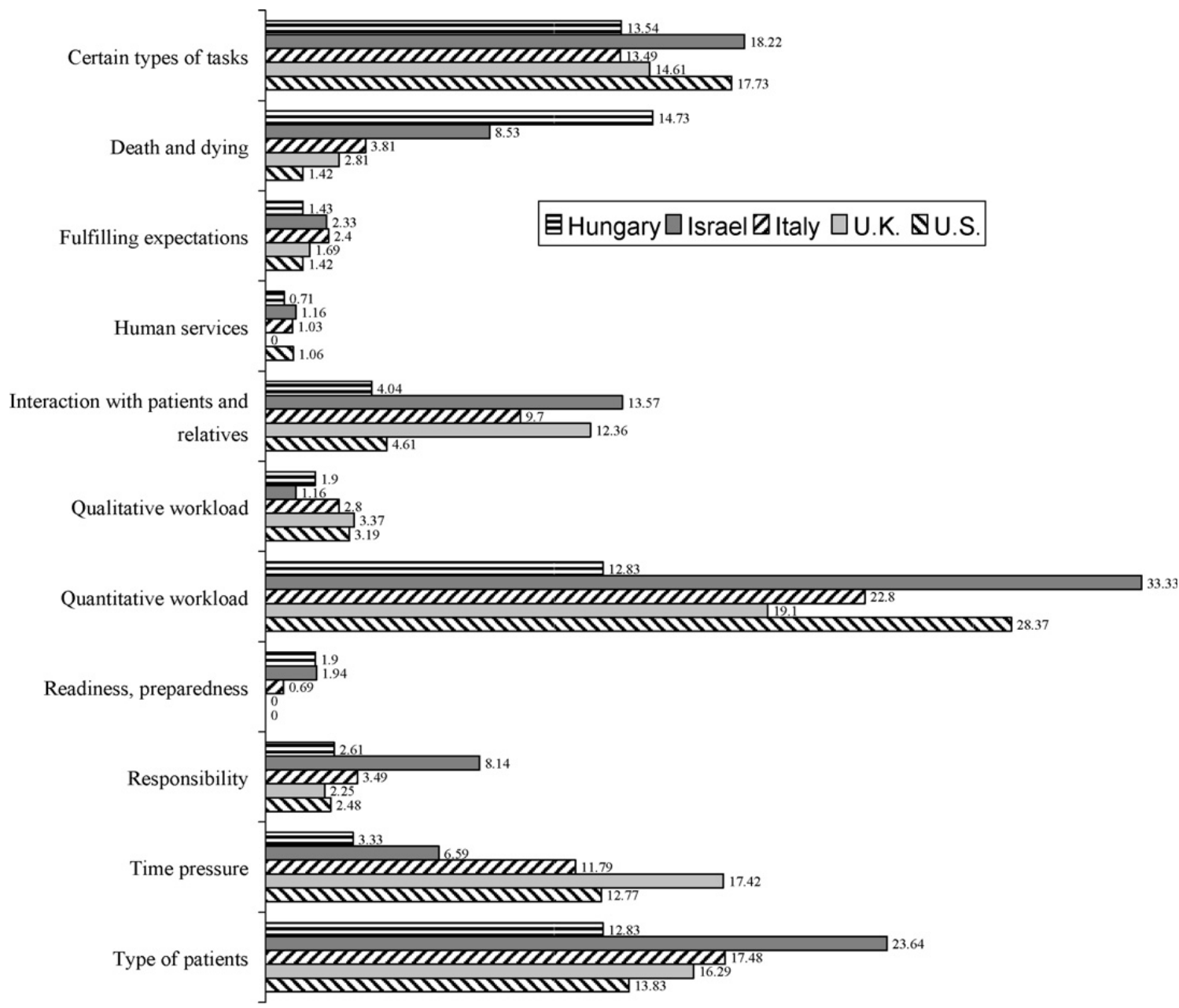

Fig. 3. Country profiles for job-related stressors. Note. Numbers to right of bars represent percent of within country sample reporting the stressor. Significant differences $(p<0.01)$ between countries were found on the following variables: (1) Death and dying — Hungary and Israel; Hungary and U.K., Hungary and U.S.; Israel and U.S. (2) Interaction with patients and relatives ${ }^{\text {acf- }}$ - Hungary and Israel; Hungary and U.K.; Israel and U.S. (3) Responsibility—Hungary and Israel. (4) Quantitative workload—Hungary and Israel; Hungary and Italy; Hungary and U.S.; Israel and U.K. (5) Time pressure-Hungary \& Italy; Hungary and U.K.; Hungary and U.S.; Israel and U.K.

$p<0.001)$. Israeli nurses differed significantly from U.K. nurses $\left(\chi^{2}(1,436)=23.72, p<0.001\right)$ and U.S. nurses $\left(\chi^{2}(1,540)=11.65, p<0.001\right)$; Hungarian nurses differed significantly from U.K. nurses $\left(\chi^{2}(1,599)=34.42\right.$, $p<0.001)$ and U.S. nurses $\left(\chi^{2}(1,703)=18.27, p<0.001\right)$. One illustrating example of conflict with co-workers is from a U.S. nurse, "... the self-righteous, arrogant attitude of fellow employees - because they are graduates of [...] School of Nursing' - making others feel as if they are inept...."

The frequency at which 'Disorganization' was written significantly differed across countries $\left(\chi^{2}(4,1428)=21.29\right.$, $p<0.001)$. Furthermore, Italian nurses reported it more frequently $(7.3 \%)$, than U.K. nurses $(0.56 \%$; $\left.\chi^{2}(1,467)=11.03, p<0.001\right)$, and U.S. nurses $\left(1.06 \% ; \chi^{2}(1,571)=13.64, p<0.001\right)$. However, this stressor was infrequently reported. Other stressors reported are administrative problems (0.48\% in Hungary; $1.06 \%$ in USA),

Table 4

Percentage of sample reporting miscellaneous stressors and strains

\begin{tabular}{|c|c|c|c|c|c|}
\hline & Hungary & Israel & Italy & U.K. & U.S. \\
\hline Miscellaneous stressors & 2.85 & 1.55 & 4.11 & 4.49 & 5.67 \\
\hline Psychological $^{\mathrm{a}}$ & 6.18 & 3.88 & 3.1 & 3.93 & 1.77 \\
\hline Behavioral & 0 & 0 & 0 & 0 & 0.35 \\
\hline Physical symptoms & 1.43 & 1.94 & 0.34 & 0.56 & 0 \\
\hline
\end{tabular}

Note. Significant differences denoted between ${ }^{\text {a}}$ Hungary and the U.S. $p<0.001$. 
under-utilization of staff/resources ( $0.39 \%$ in Israel, $0.56 \%$ in U.K.), poor organizational climate ( $0.95 \%$ in Hungary, $0.34 \%$ in Italy, $1.12 \%$ in U.K., and $0.71 \%$ in USA), and lack of development opportunities $(0.24 \%$ in Hungary, $0.34 \%$ in Italy, $3.37 \%$ in U.K., and $1.77 \%$ in USA). These stressors were infrequently mentioned and there were no significant differences between their mention across countries.

\subsubsection{Job-related stressors}

Among job-related stressors (Fig. 3) 'certain types of tasks' were reported as a source of stress or anxiety with $13.49-18.22 \%$ of the samples reporting it, but this and 'certain aspects of the job role' appeared universally stressful to nurses in all five countries (i.e., there were no significant differences between countries). One nurse from the U.S. reported "... being responsible for non-skilled ancillary staff—of which many need constant supervision and direction ..." as a stressor. This illustrates that supervising unskilled staff is a source of stress on the job. This finding is also supported by the rank order of the stressors within country; for nurses in each of the five countries, "performing certain tasks' was one of the top 10 stressors.

Dealing with 'certain types of patients' (e.g., personality) or 'patients' condition(s)' was reported invariantly across countries too (see Fig. 3) and it was one of the top 10 stressors reported in each of the five countries (see Table 3). Thus, condition and type of patient is a common source of anxiety for nurses in each of the five countries. For example, a U.S. nurse reported "agitated, combative patients" and a U.K. nurse wrote about "abusive patients." A patient's condition was reflected upon as in this account from an Israeli nurse: "Patients who do not remember, drug addicts, and all kind of characters."

Reports of 'death and dying' as a stressor significantly differed between countries $\left(\chi^{2}(4,1428)=59.95, p<0.001\right)$. Pair-wise comparison tests showed that Hungarian nurses $(14.73 \%)$ reported it more frequently than Italian nurses $\left(3.81 \% ; \chi^{2}(1,710)=22.15, p<0.001\right)$, U.K. nurses $\left(2.81 \% ; \chi^{2}(1,599)=17.89, p<0.001\right)$, and U.S. nurses $(1.42 \%$; $\left.\chi^{2}(1,703)=35.16, p<0.001\right)$. Israeli nurses reported death and dying more often $(8.53 \%)$ than U.S. nurses $\left(\chi^{2}(1,540)=14.85, p<0.001\right)$. One example of this category came from a Hungarian nurse who wrote, "It's hard to cope with my feelings about death, especially when someone dies in my hands."

'Interaction with patients and patients' relatives' was significantly different between countries $\left(\chi^{2}(4,1428)=29.77\right.$, $p<0.001)$. This stressor was more likely to be regarded as a source of stress in Israel (13.57\%) than the U.S. (4.61\%; $\left.\chi^{2}(1,540)=13.34, p<0.001\right)$, and more in the U.K. $(12.36 \%)$ than in Hungary $\left(4.04 \% ; \chi^{2}(1,599)=14.23\right.$, $p<0.001)$. One respondent from Israel wrote 'too much interruption from families' as a job-related stressor.

Reports of 'job role ambiguity' also significantly differed between countries $\left(\chi^{2}(4,1428)=17.65, p<0.001\right)$; with U.K. nurses reporting it significantly more $(4.5 \%)$ than Israeli nurses $\left(0.0 \% ; \chi^{2}(1,436)=11.81, p<0.001\right)$. However, this was a low frequency stressor in the U.K.; therefore, caution is needed in interpreting the results. 'Time pressure' reports differed significantly across countries $\left(\chi^{2}(4,1428)=4.27, p<0.001\right)$. Time pressure was reported more frequently in the U.K. $\left(17.42 \% ; \chi^{2}(1,599)=35.75, p<0.001\right)$, Italy $\left(6.59 \% ; \chi^{2}(1,710)=19.36, p<0.001\right)$, and U.S. $\left(12.77 \% ; \chi^{2}(1,703)=22.78, p<0.001\right)$ than Hungary $(3.33 \%)$. U.K. nurses also reported time pressure more often than Israeli nurses $\left(6.59 \% ; \chi^{2}(1,436)=12.60, p<0.001\right)$. To test if the number of patients per nurse ratio has anything to do with these results, a one-way ANOVA was performed. Results showed a significant difference between countries $F(4,1329)=9.18, p<0.05$. Bonferroni adjusted $(p<0.01)$ pair-wise comparisons demonstrated that Israeli nurses reported the least number of patients per nurse $(M=19.2$, S.D. $=26.44)$ and U.K. and U.S. nurses reported the highest number of patients per nurse $(M=33.77$, S.D. $=40.5 ; M=29.05$, S.D. $=31.33$, respectively $)$. The number of patients per nurse was lower in Israel $(t(2,626)=2.48, p<0.05)$ than Hungary $(M=28.82$, S.D. $=20.41)$ and U.K. $(t(2,401)=20.05, p<0.05)$, greater in the U.K. than Italy $(M=24.84$, S.D. $=14.23 ; t(2,428)=35.79, p<0.05)$, and greater in the U.S. than Israel $(t(2,501)=5.9, p<0.05)$. However, contrary to prediction, Italian nurses reported significantly fewer patients per nurse than U.K. and U.S. nurses.

\section{Discussion}

The main purpose of this study was to determine culture-specific (emic) and culture-general (etic) stressors as selfreported by nurses in each of five countries. Results of this study support Wheeler's (1997b, 1998a) contention that work overload is typical in the nursing profession, as it was ranked as one of the top 10 most frequently reported stressors in each of the countries. Thus, we further contend that work overload is likely an etic stressor in the nursing profession. However, it is necessary to qualify this claim as Israeli and U.S. nurses reported quantitative workload 
more frequently than Hungarian nurses did, and U.S. and Israeli nurses reported quantitative workload most frequently among the five countries. In other words, although quantitative workload might be a source of stress or anxiety in each country, it might be a more acute problem in Israel and the U.S. It is also likely that lack of staff is not a predictor of nurses' high workload; for example in Hungary there is an overage of physicians (Orosz \& Burns, 2000) and nurse-topatient ratios differ across nations (Glazer \& Beehr, 2005).

The study's second hypothesis, that leadership induced occupational stress is a cultural etic, was mostly not supported, because Israeli and Hungarian nurses reported the stressor less frequently than U.K. and U.S. nurses did. An interesting parallel to this result is that Hungarian (9.74\%) and Israeli nurses (10.47\%) reported problems associated with co-workers (peer level associates) least frequently too. It is possible that reporting interpersonal conflicts between colleagues is uncommon in these countries or they are not prevalent sources of stress on the job due to greater endorsement of collectivism than individualism (Hofstede, 1984). For the case of Israel, it is possible that there is a sense of community and camaraderie that is difficult to compare elsewhere. This might also reflect the geo-political situation nurses in Israel confront in comparison to nurses from the other countries. As for Hungary, we speculate that endorsement of Harmony values (Schwartz, 1994) are driving the minimal reporting of interpersonal issues with supervisor and co-workers. However, Italy, ranked high on Harmony value too, was not significantly different from the U.K. and the U.S., therefore this conclusion is tentative.

That Hypothesis 3 was supported, as Hungarian nurses reported 'lack of resources' more frequently than the U.S., might be due to the gross economic changes Hungary was enduring only six years after the fall of communism (when these data were collected). In addition to reporting lack of resources, Hungarian nurses also reported low salary as a source of stress or anxiety more often than nurses in the other countries. At the time of data collection, Hungarian nurses made the equivalent of U.S.\$1200 per year, though the cost of living in the capital was at least U.S.\$3000 per year and this amount has not changed much at all in the past decade (Gati, 2007b). Still, nurses received financial gratuities for their services from patients to supplement their salary (Gati, 2007b), and were able to make the minimum level of living, however it is probable that the thought have having to rely on these gratuities made low salary a burning problem for them. In addition to staff shortages, U.K. nurses reported skill level of current staff as an acute problem. Nurses in the U.K. complained about staff being inadequately trained and placed on the job without appropriate training. These accounts only emerged in the U.K.

Hypothesis 4 was partially supported. Nurses in the U.S. reported misdirected, negative rewards more frequently than nurses in any other country and significantly more than Hungarian and Israeli nurses. We propose that this might be partially due to the market orientation of the privately managed U.S. health-care system. In Hungary, Israel, Italy, and the U.K. health-care systems are partially or entirely government owned and managed.

Results of the exploratory statistical analyses indicated that 'performing certain tasks' and 'certain type of patients' might be etic stressors, as these categories were among the top 10 in all five countries and no between-country differences were found on the frequency to which they were mentioned. On death and dying Hungarian nurses reported it more frequently than nurses in the other countries, but not significantly different from Israel. One question that could be raised is whether there were more respondents from critical care units in Hungary and Israel than in the other countries. Based on cross-tabs analysis, the answer is negative. In Hungary 39.6\% of nurses were from critical care units (of those who gave a qualitative response $42.1 \%$ were from critical care units) and in Israel they represented $41.1 \%$ (39.2\% of qualitative responders) of the respondents. In Italy and U.K. critical care unit nurses represented above $36 \%$ of respondents (35.7\% and $38.1 \%$ of qualitative responders, respectively) and in the USA nearly $60 \%$ were in critical care units (59.2\% of qualitative responders). These statistics suggest that the unit in which nurses worked did not impact reporting of 'death and dying' as a stressor. In fact, similar to the above culture explanations for Israel and Hungary, we again assert the explanation that collectivistic and harmony values drive nurses' care for others' and nurses in these countries might not feel as detached from the patients as nurses in Italy, U.K., and USA. Moreover, Hungarian nurses were not required as much nursing education as nurses in other countries, and Israeli nurses were confronted with death and dying of young soldiers far more frequently than nurses in the other countries. In fact one of the four participating hospitals from Israel, with the largest number of respondents $(n=254,50.2 \%$ of the Israeli sample) was one that served wounded soldiers serving on the northern border of Israel.

That 'interaction with patients (and their families)' was not frequently mentioned in Hungary and USA might be due to U.S. nurses' training to deal with social interactions on the job. It is also possible that because the U.S. is the most individualistic of all five countries (Hofstede, 1984), families interfere less with patients' medical care. Furthermore, it is possible that interaction with patients, patients' families and relatives was infrequently 
mentioned in Hungary because of the endorsement of Harmony (Schwartz, 1994), such that nurses either do not report interaction with patients and patients' family problems or Hungarian nurses see it as implicit in their roles to interact with patients.

'Time pressure' as a source of stress and anxiety on the job was more frequently reported among Italian, U.K., and U.S. nurses than among Hungarian nurses. The nurse to patient ratio does not appear to influence this relationship. Therefore, it is possible that perception of time differs across cultures. Indeed, there is evidence of cultural differences of temporal perceptions (e.g., Brislin \& Kim, 2003; Dahl, 1995; Hall, 1983; Hall \& Hall, 1990; Jones, 1988). Thus, caution is warranted when assessing time pressure, as a variable labeled 'time pressure' might take on a different conceptual meaning in different countries. An interesting finding that relates to high frequency of 'time pressure' in Italy is that Italian nurses reported 'disorganization' more frequently than U.K. and U.S. nurses did. Perhaps nurses in Italy felt the work pace and environment were both hectic and disorganized, which contributed to perceptions of being under time pressure.

Lastly, between-country differences on the pair-wise test showed that nurses in Hungary and the U.K. differed significantly from each other and all the other countries on the number of stressors reported. U.K. nurses reported the most and Hungarian nurses reported the least number of stressors per respondent. These findings are counter to cultural depictions of these countries. For example Goodwin, Nizharadze, Luu, Kosa, and Emelyanova (1999) found that Hungarians self-disclose significantly more often than Georgians and Russians. In contrast, people in the U.K. are often depicted as keeping a "stiff upper lip" (The British Stiff Upper, n.d.).

\subsection{Summary}

The present study suggests that there are both etic and emic sources of job stress. Of the stressors reported, it appears that 'certain type of tasks,' 'type of patient,' and 'workload' are etic and invariant sources of stress and anxiety. However, there are a number of stressors for which the frequency differed across cultures, but they each make the top 10 list of reported stressors in each country. These stressors include resources, leadership, lack of staff, quantitative workload, and co-workers. In terms of culture-specific stressors (i.e., stressors that made the top 10 list in one or two countries, but not all five), death and dying are particularly salient in Hungary and Israel, and inadequate communication and psychological strain (see Table 4) are reported in Hungary too. Skillset of staff is frequently reported as a stressor in U.K. and Israel. In Italy, disorganization is frequently reported, along with time pressure in Italy, U.K., and USA. Negative reward and miscellaneous stressors (i.e., status in society, profession is not well respected, work-family conflict) are salient for U.S. nurses.

Although these data were collected 10 years ago, the findings are relevant both to nurse administrators, as well as to cross-cultural scholars of stress, in general, as we highlight the importance of self-report free-write data without imposing researchers' ideas of what stressors are most salient to nurses.

\subsection{Implications for future research}

Murphy (1995) proposed that the only general rule to a successful stress prevention program in health-care is to design a program that specifically addresses the unique and idiosyncratic nature of occupational stress as experienced by the employees on the job. The present study developed the first ever cross-cultural assessment of culture-specific and job-specific stressors that would allow one to develop stress prevention programs that are specifically geared to the population's occupation and cultural environment. Given the large number of respondents we ascertained in this study (as opposed to the small number of respondents typically obtained in focus-group methods), these data provide a reliable list of stressors and strains and a strong starting point for culture-tailored stress-intervention efforts. Stress management interventions in these countries would have to take the culture-specific job-related stressors into consideration when planning interventions. For example, in the U.K. a stress management intervention should take into consideration 'skillset of staff,' whereas in Hungary death and dying ought to be addressed. In the U.S., issues related to rewards need attention and in Italy general organization needs focus. In contrast, it is probably not necessary to gear a stress management intervention toward the topic of time pressure, as this was infrequently mentioned. The point here is that occupational stress interventions can now be better tailored to the needs of nurses in a specific country, by addressing the specific stressors salient to them and not a generic stress management prevention program. 


\subsection{Limitations, strengths, and future direction}

In Wheeler's (1998b) meta-analysis of occupational stress among nurses, cross-sectional survey design was argued to be the most widely used method. These surveys are most often self-report close-ended inventories. This study utilized content analysis to analyze responses to an open-ended question in which respondents could freely write-in their responses to a self-reported survey. However, in order to uncover causal relationships between stressors and strains and country-specific and culture-universals, more in-depth qualitative, experimental, and longitudinal research is warranted. Furthermore, although content analysis was used to uncover country-specific causes of job stress and anxiety, nurses only responded to one open-ended question. The methodology employed in the present study did not allow for probing and clarification. More in-depth, interview style qualitative data collection could distort initial perception of causes, but it could also lead to an understanding of other stressors that are not easily revealed otherwise. Thus, researchers can probe by asking "Can you tell me about the conditions in your workplace that are strainproducing?" or "Can you tell me about the causes of strain in your workplace or in your job?" Moreover, through indepth interviews, it is possible to reveal how individuals cope with the stressors. Do they engage in adaptive or maladaptive coping strategies? What even constitutes adaptive and maladaptive coping strategies in different contexts? For future studies it is important to consider longer, qualitative interviews to help better understand emic aspects of occupational stress. Also, one might recognize that just because respondents did not mention a stressor, it does not mean that the stressor is irrelevant or not salient.

Another limitation is related to the labeling of stressors as etic or emic. For the most part, etic stressors were those that were present in each of the studied countries and for which there was no statistical difference between the frequency of mention. Emic stressors were those that were reported more often (on the basis of Chi-square tests) in one or more country than in another(s). This process for assigning conclusions about stressors is not without its flaws. First, nurses were not given an exhaustive list from which they could rate or rank prevalence. It is possible that had a nurse been asked about certain stressors, she would have indicated that the ones she was asked about were indeed more salient than the ones she came up with alone. Second, and as a corollary to the first caution, just because a stressor is reported more or less frequently in one country than another it does not necessarily mean it is more or less salient in relation to other stressors for people elsewhere. For example, suppose (this is a hypothetical example) 'lack of staff' was reported by $40 \%$ of respondents in the USA, $25 \%$ in the U.K., 30\% in Italy, $20 \%$ in Israel, and 14\% in Hungary, and that these frequencies were significantly different from each other. Next, suppose for U.S., U.K. and Italian nurses, it ranks as the \#1 most salient stressor and for Israeli and Hungarian nurses it ranks as the 2nd and 6th, respectively, most salient stressors of the 33, it probably could not be concluded that 'lack of staff' is an emic variable.

Wheeler (1997a) further cautions that stressors uncovered by either quantitative or qualitative methods are not foolproof in the sense that anticipation of future strains and current inability to deal with a task might influence what gets perceived as a stressor. According to our findings, for example, Hungarian and Israeli nurses reported death and dying as stress-producing. This might be due to insufficient training of Hungarian nurses about death and dying and the fact that one of the Israeli hospitals attends to soldiers serving on Israel's volatile northern border.

Another limitation of this study might be related to the order in which the question analyzed for this study was presented in the survey. In Israel, it was the last question on the second of the 10 pages, and in the other countries it was the last question of the 10-page long survey preceded by quantitative questions. This might have introduced order bias; Israeli nurses might have listed stressors that were on the forefront of their minds, whereas nurses from other countries might have only reported stressors that were not covered by the quantitative portion of the survey. Although this limitation is a viable one, it should be noted that the Israeli and the U.S. nurses reported work overload as a highly salient stressor. Since role overload was an item on the quantitative portion of the survey, it is probably safe to conclude, at the least, that workload is a pervasive problem that warranted further emphasis by nurses.

Finally, that the data are from over a decade ago could potentially limit the generalizability of the data. For example, in 1994 nurses indicated staff shortages second most frequently than any other stressor. However, in a publication of the European Observatory on Health-care Systems, Rosen (2003) concluded that despite lower levels of 'nurse to inhabitants' ratio, by the end of 2000 Israel did not have a nursing shortage problem. This might be due to increase hiring of nurses or a difference in objective and subjective reality. Given that the last major nursing strike in Israel was in 1980, which led to the establishment of a minimum nurse to bed ratio (Rosen), we believe the latter conclusion is 
more likely. Rosen does not account for absences and he also, admittedly, does not take into account the qualitative care of patients that might differ across cultures. Indeed, type of patient was the third most reported stressor among Israelis. Thus, we believe the information is still highly useful for at least four reasons. First, environmental and organizational problems (typically associated with budgetary matters) in these countries have mostly not changed over the course of time (e.g., Gati, 2007a,b; Reuters, 2007; Woolf, 2007). Second, this study clearly demonstrates that certain stressors for nurses are common across these cultures and are inherent in nursing. Third, results from this study show that there are cultural differences in indicators of stress and anxiety. These types of stressors might not necessarily be inherent in nursing, but instead a result of organizational and/or national constraints in budgeting, health-care rules, regulations, and laws, and other cultural characteristics. Fourth, and related to the third benefit is that the data can serve as a baseline for continued surveillance of stress in the nursing profession in these countries (Quick et al., 1998). Regular surveillance is an important primary prevention tactic however, it is also one of the costliest ways, because it requires organizations to recognize their own shortcomings when it comes to stress prevention (Cooper et al., 2001).

This study illuminates the need for more qualitative research on the proximal causes of job stress. In this way we are able to better understand the idiosyncratic experience of work stress within cultures and across cultures. Results presented here can guide further qualitative and quantitative studies by providing information on particularly stressful aspects of nurses' work in each of the five countries. The findings can also guide stress-intervention programs by helping consultants focus on potential stressors that might not have been obvious before this study. These opportunities, however, do not preclude further investigation of the prevalent stressors within a particular organization prior to implementation of a prevention or intervention strategy.

\section{Acknowledgements}

The authors appreciate the help of Rachel Glazer and Paulo Guggia for transcribing and translating the Hebrew and Italian survey responses, respectively. We also thank Jennifer Loesch for transcribing the U.S. and U.K. survey responses and both Jennifer and Candice Yee for their assistance in coding qualitative data. We are also grateful to Dr. Terry A. Beehr, Dr. Nancy DaSilva, and Dr. Elena Klaw for their helpful comments on earlier versions of this manuscript.

\section{References}

Baba, V. V., Galperin, B. L., \& Lituchy, T. R. (1999). Occupational mental health: A study of work-related depression among nurses in the Caribbean. International Journal of Nursing Studies, 36, 163-169.

Beehr, T. A., \& Glazer, S. (2001). A cultural perspective of social support in relation to occupational stress. In P. Perrewé, D. C. Ganster, \& J. Moran (Eds.), Research in occupational stress and well-being (pp. 97-142). Greenwich, CT: JAI Press.

Beehr, T. A., \& Glazer, S. (2005). Organizational role stress. In J. Barling, K. Kelloway, \& M. Frone (Eds.), Handbook of work stress (pp. 7-33). Thousand Oaks, CA: Sage.

Beehr, T. A., Jex, S. M., Stacy, B. A., \& Murray, M. A. (2000). Work stressors and coworker support as predictors of individual strain and job performance. Journal of Organizational Behavior, 21, 391-405.

Beehr, T. A., \& Newman, J. E. (1978). Job stress, employee health, and organizational effectiveness: A facet analysis, model, and literature review. Personnel Psychology, 31, 665-699.

Bhagat, R. S., O’Driscoll, M. P., Babakus, E., Frey, L., Chokkar, J., Ninokumar, B. H., et al. (1994). Organizational stress and coping in seven national contexts: A cross-cultural investigation. In G. P. Keita \& J. J., Hurrell, Jr., (Eds.). Job stress in a changing workforce: Investigating gender, diversity, and family issues (pp. 93-105). Washington, DC: American Psychological Association.

Brislin, R. W., \& Kim, E. S. (2003). Cultural diversity in people's understanding and uses of time. Applied Psychology: An International Review, 52, 363-382.

Bureau of Labor Statistics, U.S. Department of Labor. (2002/2003). Occupational Outlook Handbook, 2002-2003 ed., Registered Nurses. Retrieved December 19, 2003, from http://www.bls.gov/oco/ocos083.htm.

Cooper, C. L., Dewe, P. J., \& O'Driscoll, M. P. (2001). Organizational stress: A review and critique of theory, research, and applications. Thousand Oaks, CA: Sage.

Dahl, Ø. (1995). When future comes from behind: Malagasy and other time concepts and some consequences for communication. International Journal of Intercultural relations, 19(2), 197-209.

Fleiss, J. L. (1981). Statistical methods for rates and proportions (2nd ed.). New York: Wiley.

French, J. R. P., Caplan, R. D., \& Van Harrison, R. (1982). The mechanisms of job stress and strain. Chichester, UK: Wiley.

Gati, J. (2007a). Healthcare under the knife. The Hungarian Quarterly 48(185) Retrieved May 23, 2007, http://www.hungarianquarterly.com/no185/ 4.html. 
Gati, J. (2007b). The grateful patient. The Hungarian Quarterly 48(185) Retrieved May 23, 2007, http://www.hungarianquarterly.com/no185/4.html.

Glazer, S. (1999). A cross-cultural study of job stress among nurses. Dissertation Abstracts International: Section B: The Sciences \& Engineering, 60(4-B), 1895.

Glazer, S. (2002). Past, present, and future of cross-cultural studies in Industrial and Organizational psychology. In Cooper, C. L., \& Robertson, I. T. Eds. International review of industrial and organizational psychology. 17 (pp.145-186). Chichester, UK: Wiley.

Glazer, S., \& Beehr, T. A. (2005). Consistency of implications of three role stressors across four countries. Journal of Organizational Behavior, 26, 467-487.

Goodwin, R., Nizharadze, G., Luu, L. N., Kosa, E., \& Emelyanova, T. (1999). Glasnost and the art of conversations: A multilevel analysis of intimate disclosure across three former communist cultures. Journal of Cross Cultural Psychology, 30, 72-90.

Hall, E. T. (1983). The Dance of Life: The Other Dimensions of Time. New York: Anchor Press.

Hall, E. T., \& Hall, M. R. (1990). Understanding Cultural Differences. Yarmouth, ME: Intercultural Press.

Hofstede, G. (1984). Culture's consequences: International differences in work-related values (Abridged ed.). Newbury Park, CA: Sage.

Jex, S. M., \& Beehr, T. A. (1991). Emerging theoretical and methodological issues in the study of work-related stress. Research in Personnel and Human Resources Management, 9, 311-365.

Jex, S. M., Beehr, T. A., \& Roberts, C. K. (1992). The meaning of occupational stress items to survey respondents. Journal of Applied Psychology, 77, 623-628.

Johns, G., \& Xie, J. L. (1998). Perceptions of absence from work: People's Republic of China versus Canada. Journal of Applied Psychology, 83, $515-530$.

Jones, J. M. (1988). Cultural differences in temporal perspectives. In J. E. McGrath (Ed.), The Social Psychology of Time: New perspectives (pp. 2138). Newbury Park, CA: Sage.

Krippendorf, K. (1980). Content analysis: An introduction to its methodology. Beverly Hills, CA: Sage.

Laungani, P. (1993). Cultural differences in stress and its management. Stress Medicine, 9, 37-43.

Lazarus, R. S., \& Folkman, S. (1984). Stress, appraisal and coping. New York: Springer.

Lu, L., Tseng, H. J., \& Cooper, C. L. (1999). Managerial stress, job satisfaction and health in Taiwan. Stress Medicine, 15, 53-64.

Miller, K., Greyling, M., Cooper, C., Lu, L., Sparks, K., \& Spector, P. E. (2000). Occupational stress and gender: A cross-cultural study. Stress Medicine, 16, 271-278.

Murphy, L. (1995). Occupational stress management: Current status and future directions. In Cooper, C., \& Rousseau, D. Eds. Trends in organizational behavior. 2 (pp.1-14). New York: Wiley.

OECD Factbook 2007. (2007). Economic, Environmental and Social Statistics. Retrieved May 23, 2007, http://ocde.p4.siteinternet.com/publications/doifiles/302007011P1T106.xls.

Orosz, E., \& Burns, A. (2000). The healthcare system in Hungary. Paris: OECD. Retrieved August 30, 2004, http://www.oecd.org/dataoecd/13/40/ 1883815.pdf.

Quick, J. D., Quick, J. C., \& Nelson, D. L. (1998). The theory of preventive stress management in organizations. In C. L. Cooper (Ed.), Theories of organizational stress (pp. 246-268). New York: Oxford University Press.

Reuters 23 April. (2007). Hungary's new health minister promises reform. Retrieved May 23, 2007, http://www.alertnet.org/thenews/newsdesk/ L23210431.htm.

Rosen, B. (2003). Health care systems in transition: Israel.. In Thomson, S., \& Mossialos, E. Eds. European observatory on health care systems, vol. 5(1)Copenhagen: The European Observatory on Health Care Systems. Retrieved May 24, 2007, http://www.israelhpr.org.il/FileServer/ 8ff3954e453f19c5a6f7cf288fefe17d.pdf.

Schaufeli, W. B., \& Janczur, B. (1994). Burnout among nurses: A Polish-Dutch comparison. Journal of Cross-Cultural Psychology, $25,95-113$.

Schwartz, S. H. (1994). Beyond individualism/collectivism: New dimensions of values. In U. Kim, H. C. Triandis, C. Kagitçibasi, S. C. Choi, \& G. Yoon (Eds.), Individualism and collectivism (pp. 85-119). Newbury Park, CA: Sage.

Semmer, N. K., McGrath, J. E., \& Beehr, T. A. (2005). Conceptual issues in research on stress and health. In C. L. Cooper (Ed.), Handbook of Stress and Health (2nd ed., pp. 1-43). New York: CRC Press.

Siu, O. L., \& Cooper, C. L. (1997). Occupational stress, job satisfaction and mental health among employees of an acquired TV company in Hong Kong. Stress Medicine, 13, 99-107.

Spector, P. E., Cooper, C. L., \& Aguilar-Vafaie, M. E. (2002). A comparative study of perceived job stressor sources and job strain in American and Iranian managers.. Applied Psychology: An International Review, 51, 446-457.

Spector, P. E. et al. (2004). A cross-national comparative study of work-family stressors, working hours, and well-being: China and Latin America vs. the Anglo world. Personnel Psychology, 57, 119-142.

The British Stiff Upper Lip. (n.d.). http://www.sterlingtimes.org/memorable_images61.htm. Retrieved January 3, 2007.

Wheeler, H. H. (1997a). Nurse occupational stress research 2: Definition and conceptualization. British Journal of Nursing, 6, 710-713.

Wheeler, H. H. (1997b). Nurse occupational stress research 3: A model of stress for research. British Journal of Nursing, 6, 944-949.

Wheeler, H. H. (1998a). Nurse occupational stress research 5: Sources and determinants of stress. British Journal of Nursing, 7, 40-43.

Wheeler, H. H. (1998b). Nurse occupational stress research 6: Methodological approaches. British Journal of Nursing, 7, $226-229$.

Wong, T. W., Chen, W. Q., Yu, T. S., Lin, Y. Z., \& Cooper, C. L. (2002). Perceived sources of occupational stress among Chinese off-shore oil installation workers. Stress and Health, 18, 217-226.

Woolf, M. (2007). NHS staff shortages? Call Robo-nurse! The Independent. Retrieved May 23, 2007, http://news.independent.co.uk/uk/ health_medical/article2562763.ece.

World Bank (n.d.). Health topic indicators 2002. Retrieved May 25, 2005, http://devdata.worldbank.org/external/dgsector.asp?W=0\&RMDK= $110 \&$ SMDK $=473886$. 